\title{
Structural and Attitudinal Barriers to Bicycle Ownership and Cycle-Based Transport in Gauteng, South Africa
}

\author{
G. T. H. Ellison ${ }^{1,2}$ (1) T. De Wet ${ }^{1}$
}

Received: 18 July 2020 / Accepted: 13 August 2021 / Published online: 5 March 2022

(c) The Author(s) 2022

\begin{abstract}
Policies that aim to facilitate and promote non-motorised transport (NMT), and in particular cycling, have been developed by many high-income countries facing increasingly congested roads and saturated public transport systems. Such policies are also emerging in many low- and middle-income settings where high rates of urbanisation have led to similar problems with motorised transport. The aim of the present study was to better understand the potential structural and attitudinal barriers to cycle-based transport in one such context: South Africa's Gauteng Province, the industrial powerhouse of sub-Saharan Africa that has recently made a firm commitment to NMT. The study focussed on demographic and socioeconomic variation in bicycle and car ownership, and related this to: (1) the reported use of motorised and non-motorised transport (both private and public); and (2) perceived 'problems' with cycling. The analyses drew on interviews with key respondents from $n=27,490$ households conducted in 2013 as part of the third Quality of Life survey undertaken by the Gauteng City Regional Observatory. The survey contained items on three outcomes of interest: household vehicle ownership (bicycles and cars); modes of transport used for the "trips" most often made; and respondents" "single biggest problem with... cycling". Respondent- and household-level demographic and socioeconomic determinants of these outcomes were examined using descriptive and multivariable statistical analyses, the latter after adjustment for measured potential confounders identified using a theoretical causal path diagram (in the form of a directed acyclic graph). Of the $n=26,469$ households providing complete data on all of the variables examined in the present study, only $n=8722(32.9 \%)$ owned a car and fewer still $(n=2244 ; 8.4 \%)$ owned a bicycle. The ownership of these assets was commonest amongst wealthier, economically active households; and those that owned a car had over five times the odds of also owning a bicycle, even after adjustment for potential confounding (OR 5.17; 95\% CI 4.58, 5.85). Moreover, of household respondents who reported making 'trips' during the preceding month $(n=18,209)$, over two-thirds of those whose households owned a car $(70.1 \%)$ reported private car-based transport for such trips, while only $3.2 \%$ of those owning a bicycle reported cycling. Amongst the specific responses given to the item requesting the "single biggest problem with... cycling" by far the commonest was "Don't know how to cycle" (32.2\%), less than half as many citing "Vehicle accident risk" (15.9\%), and fewer still: "Destination is too far" (13.9\%); "Crime" (10.3\%); "Too much effort" (9.2\%); or "Lack of good paths" (4.6\%). While the first of these reasons was commonest amongst poorer households, concerns about risk and effort were both most common amongst better educated, economically active and wealthier/better serviced households. In contrast, concerns over (cycle) paths were only common amongst those owning bicycles. The low prevalence of household bicycle ownership, and the disproportionate number of households owning bicycles that also owned cars, might explain the very small proportion of the 'the trips most often made' that involved cycle-based transport $(0.3 \%)$, and the preferential use of cars amongst households owning both bicycles and cars. Low levels of bicycle ownership might also explain why so many respondents cited "Don't know how" as the "single biggest problem with... cycling"; although risk and effort were also substantial concerns (presumably for many who did, and some who did not, know how to cycle); the lack of suitable cycle lanes being only primarily a concern for those who actually owned bicycles. Structural and attitudinal barriers to cycle-based transport limit the use of cycle-based transport in Gauteng, not only amongst the vast majority of household respondents who lack the means to cycle (and the means to learn how), but also amongst those dissuaded from learning to cycle, purchasing a bicycle and/or using a bicycle they own by: the risks and effort involved; the lack of suitable cycle paths; and/or because they also own a car and prefer to drive than cycle.
\end{abstract}

Extended author information available on the last page of the article 
Keywords Cycling Cycle lanes · Non-motorised transport · South Africa directed acyclic graph

\section{Introduction}

Cycling is considered one of the most efficient modes of transport for short journeys, as well as for the "first or last mile" of longer commutes when integrated with public transport [16, 29, 37, 39]. This is because cycling costs far less than private or public motorised transport, both in terms of direct user costs and public infrastructure costs $[14,15,32,36]$. As a result, cycling is considered one of the most equitable modes of transport available, being far more accessible to those with modest means than either public transport or private cars [35]. More recently, there has been renewed interest in the environmental and health benefits of cycling, given it causes virtually no noise or air pollution,requires far less space than roads; poses less danger to pedestrians [22], and consumes far fewer nonrenewable resources than motorised transport [39], while cycling also offers a valuable source of regular cardiovascular exercise [9].

Policies that aim to facilitate and promote non-motorised transport (NMT), and in particular cycling, have been developed by many high-income countries facing increasingly congested roads and saturated public transport systems [39]. Many of these have been inspired by the high levels of cycling in the Netherlands and Denmark, both of whom are established global leaders with high levels of cycle-based transport [1]. Indeed, the prevalence of cycling has recently experienced a substantial increase in cities where it has been far less commonplace in the past including, for example, Paris, London, Barcelona, and Dublin [10, 31]. All of these cities have implemented transport policies that aim to facilitate and encourage cycle-based transport, and each have invested in new cycle infrastructure (and improvements in existing infrastructure) over the past 10-20 years to enhance and extend levels of cycling [10, 14, 20,31]. Similar initiatives have emerged in the urban centres of middle- and low-income countries where high rates of urbanisation and limited investment in transport infrastructure have led to similar problems with motorised transport (i.e. increasingly congested roads and saturated public transport systems [1, $11,38,45])$. The aim of the present study was to better understand the potential structural and attitudinal barriers to cycle-based transport in one such context: South Africa's Gauteng Province-the industrial powerhouse of sub-Saharan Africa; South Africa's most urbanised Province; and one that recently made a firm commitment to NMT [24, 25].

Despite, and perhaps as a result of, South Africa's status as sub-Saharan Africa's dominant economy, cycling has largely been overlooked as a potential form of transport in the country's urban centres [2, 3, 23, 33, 34]. South Africans tend to view cycling primarily as a means of recreation for the wealthy or a mode of transport for the poor $[6,27,30]$, and the country still lacks a single bicycle factory - a fact that is all the more remarkable given it was the first to have a BMW manufacturing plant outside Germany [4]. In this context, and given its high rate of urbanisation [45], South Africa appears an ideal context in which to implement and evaluate cycling as part of sustainable NMT within urban and rapidly urbanising middle-income contexts. Indeed, the City of Johannesburg's response to the 2009 National Policy on NMT [5] involved a series of integrated local policies that aim to provide both the comprehensive framework and the enabling political commitment required to ensure City stakeholders can address the challenges inherent to NMT [5-7]. These policies include measures developed in collaboration with the Johannesburg Roads Agency [25] and the Johannesburg Development Agency [24], to provide more support for the safe movement of pedestrians and cyclists, thereby creating a transport system in which cycling and walking become 'commuting and travelling modes of choice', alongside public transport, for all city residents.

Given that the road networks in Johannesburg (as in most South African cities) were not originally designed to accommodate and safeguard commuters making use of NMT (whether walking or cycling [41]), a central plank of Johannesburg's integrated NMT policies involves a commitment to invest in the infrastructure required for short and long cycle-based journeys, and integrating this infrastructure with public transport hubs [16, 29, 37, 39]. Based on this commitment, the City of Johannesburg's recent 'Strategic Integrated Transport Plan Framework' [6] outlined a number of the strategies focussing specifically on the provision and uptake of cycling infrastructure, including:

- the construction of dedicated high-quality cycle lanes;

- the integration of cycling with public transport;

- dedicated NMT projects focusing on schools, university students, and the general public;

- increasing the availability of bicycles; and

- an awareness and social marketing programme to make cycling "cool" and encourage more people to make use of cycle-based transport.

While much of the focus of these strategies has been on identifying routes where cycle-based transport might be feasible (and what infrastructure might be required to: improve the suitability of these routes for cycling; and ensure they 
are better integrated with public transport), they also recognise access to bicycles and attitudes towards travelling by bicycle as key to their potential success. With this in mind, the present study examined potential structural and attitudinal barriers to cycle-based transport across Gauteng. The study used data from the third Quality of Life household survey (QoL-III) undertaken by the Gauteng City Regional Observatory (GRCO) in 2013, prior to the completion of Johannesburg's proposed cycle lanes. It aimed to identify demographic and socioeconomic determinants of bicycle and car ownership, and to evaluate their potential impact on: the reported use of motorised and non-motorised transport (both private and public); and perceived 'problems' with cycle-based transport. As such, the present study aimed to identify structural and attitudinal barriers to bicycle ownership and cycle-based transport in Gauteng, and to identify what additional measures might be required for the successful implementation and uptake of NMT policies within the Province and beyond.

\section{Methods}

\section{The Gauteng City Regional Observatory's Third Quality of Life Household Survey}

The GCRO was established in 2008 as a partnership between the University of Johannesburg, the University of the Witwatersrand and the Gauteng Provincial Government, with the intention of providing up-to-date information on "a fast growing and dynamic urban region" to support "better planning and management, and... improved co-operative government relations" [19]. To this end, the GCRO has conducted a series of Quality of Life (QoL) household surveys to "analyse the quality of life of citizens, identify key areas and groups needing intervention and support, and provide a holistic assessment of life in the Gauteng City-region" [19]. Field work for the GCRO's QoL-III survey was completed in July 2013 using a digital questionnaire uploaded to electronic tablets on which information was collected from fieldworker observations and interviews with a single key informant/respondent per household. These interviews focussed on the living conditions, socioeconomic position, "values and attitudes of citizens, their levels of social capital, alienation, and anomie" [19]. The primary sampling frame for the QoL-III survey was based on 2011 local electoral wards, with random sampling implemented at small area level within each electoral ward and a dedicated KISH grid for the selection of key household informants [19]. Despite fieldworkers experiencing difficulties accessing residential dwellings within industrial areas and secure gated communities, the survey succeeded in collecting data from $n=27,490$ households across all 508 of Gauteng's electoral wards and all ten municipalities. Quality assurance of data collection involved the use of two independent contractors: one to conduct fieldwork/data collection; the other (present throughout the duration of fieldwork) to undertake random and specific back-checking of these data as they were collected. Further quality assurance was provided by Statistics South Africa, and the University of the Witwatersrand [19].

\section{Selection and Coding of Items from the GCRO QoL-III Questionnaire}

The questionnaire used in the GCRO's QoL-III survey contained more than 300 items within separate modules (i.e. sections) focussing on: location information; fieldworker observations; household information; population mobility and migration; neighbourhood amenities; transport; community participation; the performance of local and national government (including satisfaction with service delivery); socio-political attitudes and behaviours; satisfaction with family life; employment and work opportunities; experience of, and attitudes towards, crime; social capital and social cohesion; health; educational attainment; and income. These items included four relevant to the outcomes of interest in the present study: household car and bicycle ownership; the role of cycling within self-reported transport practices; and perceived barriers to cycling.

A single question within the household circumstances module asked: "Does this household have any of the following that are in good working order, that is not broken?" to which both "Bicycle" and "Car" were two of nine answers available (the others being: "Radio, CD player or music system"; "Television"; "TopTV, DSTV and/or MNET [subscription television channels]"; "Cell [mobile] phone"; "Telephone or landline"; "Personal computer or laptop"; and "Internet connection"). In the present study the responses to this question were used to generate two separate variables regarding bicycle and car ownership (and a third for television ownership, as a separate measure of household assets; see below), each recoded as either: 'Owned' or 'Not owned'. The questionnaire also included a suite of secondary transport-related items situated immediately after asking respondents to: "Think about the trip that you make most often that involves walking or cycling or other mode of transport such as a taxi, car or train..." (the 'trip made most often') and to: "Think about the last time you made this trip, from your home to your destination (one way)...". Two subsequent items included "Cycling" as one of the potential answers, the first asking: "What were all the different types of transport you used to make the trip?"; the second asking: "Thinking about the LONGEST distance travelled as part of your trip, what type of transport did you use for this part of the trip?". For the purposes of the present study, the answers to both of these questions were recoded as: 'Cycling', 'By private car' 
("Car as driver", "Car as passenger" or "Car as passenger through a lift club”), 'Motorbike', 'Public transport' ("Taxi”, "Gautrain", "ReaVaya bus [BRT Joburg]", "Other bus" or "School bus") 'Walking' ("Walk”) or 'Other' ("Other type of transport"), together with a separate category for the surprising number of respondents who reported that they had not made any trips from their house in the preceding month (a response that interviewers were required to carefully probe to minimise misreporting errors). Finally, one of the last questions in the transport module asked: "What is the single biggest problem with walking or cycling to work, the shops or anywhere, not for exercise (even if you do not walk or cycle)" with separate responses available for 'cycling' and 'walking', coded into twelve categories, ten of which related to specific cycling-related "problems": "Crime"; "Destination is too far"; "Vehicle accident risk"; "Lack of good paths"; "It takes too long"; "Too much effort"; "Poverty status"; "No shower at destination"; "No lock up facility at destination"; and "Don't know how to cycle"), one for "Other" problems (i.e. those falling outside these categories) and one for respondents who were unable to offer an answer ("Don't know or no opinion"). The ten specific responses were recoded as ten separate variables, each coded simply as 'Present' or 'Absent', with responses recorded as 'Absent' where these were for one of the other nine specific responses or "Other" (but not responses recorded as "Don't know or no opinion”, which were recoded as 'Missing').

Items relevant to individual-level demographic and socioeconomic predictors of car and cycle ownership, and on the cycling behaviours and attitudes of respondents included: gender; population group classification (a marker of racial/ ethnic identity based upon fieldworker observations and categorised according to the apartheid-era 1950 Population Registration Act [which was repealed in 1991] as: 'African'; 'Asian/Indian'; 'Coloured'; or 'White'); age (categorised into: $18-25$ years; $26-35$ years; $36-45$ years; 46-60 years; or $>60$ years); educational attainment (categorised into: 'Grade 8 or above', equivalent to at least some secondary education; and 'Grade 7 or below', equivalent to only some, if any, primary education); and employment status (recoded from the survey's twelve separate categories into: 'Unemployed', including those looking and not looking for work, those preoccupied with household or caring responsibilities, the disabled, the retired and students; or 'Employed', which included those employed full- and part-time in both the 'formal' and 'informal' sectors, and in their own businesses).

Items relevant to area-level and household-level socioeconomic indices included: municipality (based on the municipality in which each household was based, coded as 'Emfuleni', 'Midvaal', 'Lesedi', 'Mogale City', 'Randfontein', 'Westonaria', 'Merafong City', 'Ekurhuleni', 'City of Johannesburg' or 'City of Tdhwane'); housing tenure (categorised as either: 'Rented' or 'Owned'); the type of dwelling occupied by the household (as categorised by the GCRO, based on the construction materials used, as either: 'Formal' or 'Informal' [18]); a derived household crowding index (determined by: dividing the total number of household members by the number of rooms occupied by each household; splitting the range of values into two equal samples at the median value; and coding these as either the 'Most crowded' or 'Least crowded' households); whether households had access to all three basic services (categorised into households who had 'All three' or 'Two or less' of: piped water, mains electricity and a separate toilet); and, finally, whether households owned a key asset (a television "in good working order", categorised simply as 'Owned' or 'Not owned').

\section{Statistical Analysis}

Descriptive statistical analyses were used to compare the distribution of area-, household- and individual-level demographic and socioeconomic characteristics amongst: (1) all QoL-III respondents and those with complete data on all of the variables examined in the present study, to assess the risk of selection bias; and (2) respondents whose households owned a car and/or a bicycle. Descriptive statistics were also used to describe the prevalence of cycling (and other forms of transport) during 'the trip most often made'; and the proportion of such trips in which cycling (as opposed to other forms of transport) was used to complete "the LONGEST distance travelled as part of your trip". All results are presented as frequencies (with percentages in parentheses), with Pearson's Chi-squared used to assess their statistical precision.

Multivariable logistic regression analyses were then used to examine: the relationship between household- and individual-level demographic and socioeconomic characteristics and household car, and bicycle, ownership; and the most commonly cited "problems" with cycling, before and after adjustment for potential confounding from measured covariates. Measured potential confounders were identified using a causal path diagram (developed in the form of a Directed Acyclic Graph [DAG] using www.dagit ty.net to verify the covariate adjustment sets required [42, 43]. This is a theory-driven analytical approach which assumes that only covariates that temporally precede both the variable acting as the specified 'exposure of interest', and the variable acting as the specified 'outcome of interest' can act as potential confounders [26] — an approach that minimises inappropriate adjustment for covariates acting as mediators or consequences of the outcome, but remains vulnerable to "residual confounding" (due to measurement error) and "unmeasured confounding" from 


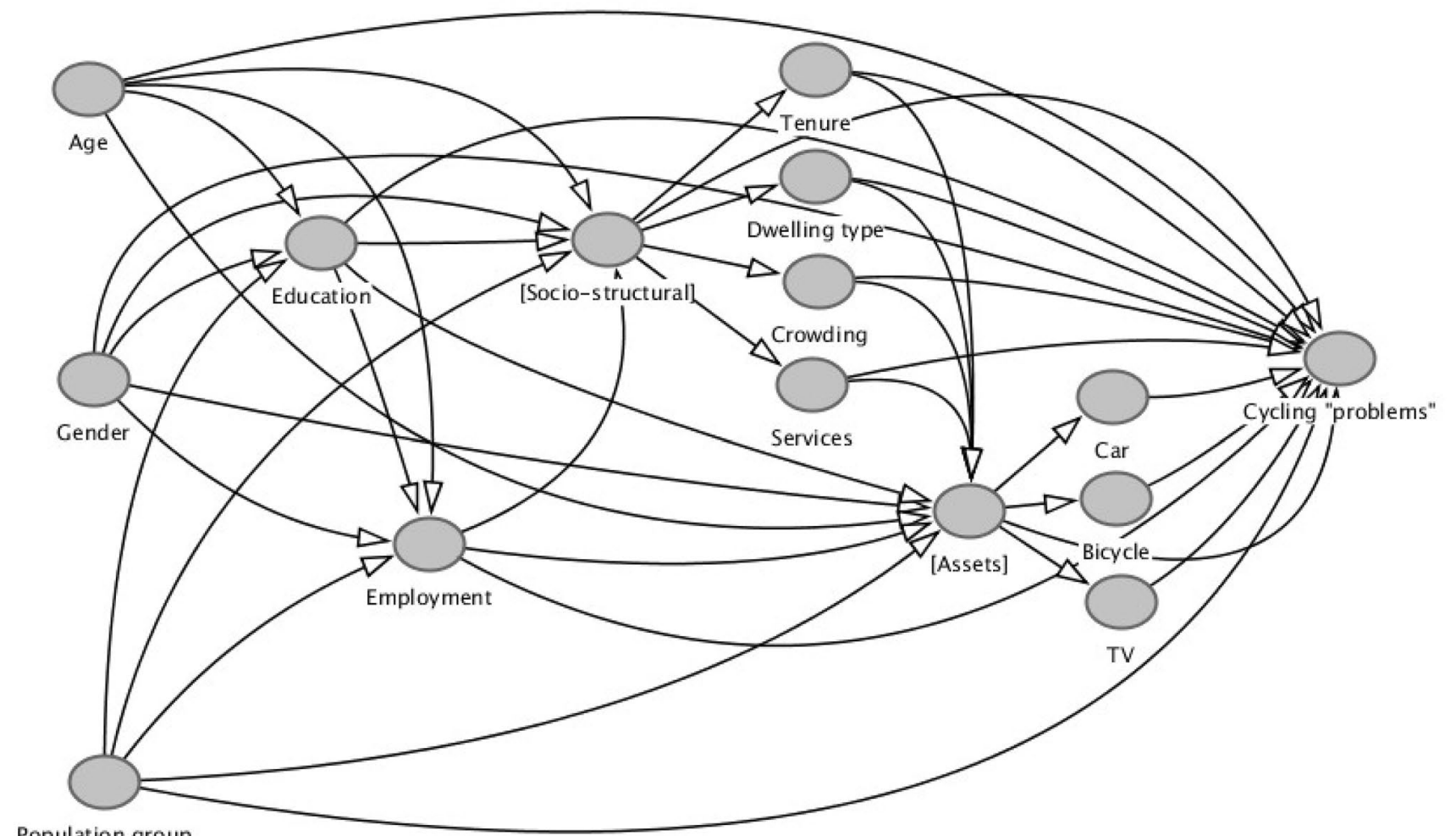

Population group

Fig. 1 Theoretical causal path diagram (represented in the form of a Directed Acyclic Graph [DAG] using the online program DAGitty: dagitty.net $[43,44])$ describing the presumed temporal sequence ${ }^{1}$ of the measured variables examined in the present study, and the postulated existence of unmeasured ([latent]) variables determining "simultaneously crystallising" clusters of those variables associated with: the socio-structural properties of households (tenure, type of dwelling, crowding and services); and key household assets (television, bicycle and car ownership). This hypothesised model was then used to determine the covariate adjustment sets required to adjust for potential confounding when each of the measured covariates

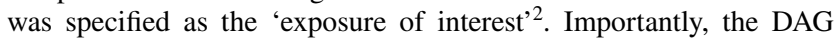

unmeasured (i.e. 'latent') covariates for which adjustment is not possible [46]. The model developed for use in the present study assumed that age, gender and population group classification were all determined simultaneously (at birth), and that these all influenced educational attainment, employment status, and household socio-structural characteristics (tenure, type of dwelling, household crowding and household services) in that order; and that these, in turn, affected the ownership of assets (television, bicycle and/or car), and thereafter perceived "problems" with cycling, in a sequential fashion (see Fig. 1). This model therefore prescribed the sequence in which measured potential confounders were included in each of the covariate adjustment sets used by multivariable logistic analyses estimating the (confounder-adjusted) relationship between those variables specified as the 'exposure of interest' and each cycling-relevant 'outcome'. This involved including does not display innumerable, additional unmeasured/unknown (latent) confounders that are also likely to be present throughout. ${ }^{1}$ See: Ellison GTH. Journal of Statistics and Data Science Education 2021;29:202-213 (and Supplementary Online Materials). ${ }^{2}$ When individual-level age, gender or population group classification were specified as the 'exposure of interest' they were adjusted for one another; while individual-level measures of education and employment were only adjusted for preceding variables. In contrast, when each of the household-level socio-structural characteristics and assets were specified as the 'exposure of interest', these were only adjusted for preceding variables (i.e. not for one another)

gender, age and population classification in all analyses examining any of these as the 'exposure of interest'; while educational attainment, employment and each cluster of household socio-structural variables were then adjusted for any preceding variables but not for those likely to have occurred (or "crystallising") simultaneously (see Fig. 1). All analyses were conducted in STATA-IC 13 (Stata Corp, USA).

\section{Ethical Approval}

The present study used publicly available anonymised datasets based on information collected by the GCRO's QoL-III survey [18], for which formal ethical approval was obtained from the University of the Witwatersrand research ethics committee [19]. 
Table 1 The distribution of individual- and household-level characteristics, and transport-relevant variables amongst: key respondents from all of the households included in the GRCO QoL-III survey
(2013; including those with missing data for one or more variable); and those with complete data on all of the variables examined in the present study

\begin{tabular}{|c|c|c|}
\hline Sample & $\begin{array}{l}\text { All households included in the GCRO QoL-III } \\
\text { survey (regardless of missing data) } n=27,490\end{array}$ & $\begin{array}{l}\text { All households included in the GCRO } \\
\text { QoL-III survey (providing complete data) } \\
n=26,469\end{array}$ \\
\hline Characteristic & $n(\%)$ & $n(\%)$ \\
\hline \multicolumn{3}{|l|}{ Individual-level characteristics } \\
\hline \multicolumn{3}{|l|}{ Age category } \\
\hline $18-25$ years & 5478 (19.9) & $5334(20.1)$ \\
\hline $26-35$ years & $7461(27.1)$ & $7199(27.2)$ \\
\hline $36-45$ years & $5768(21.0)$ & $5567(21.0)$ \\
\hline $46-60$ years & $5573(20.3)$ & $5337(20.2)$ \\
\hline$>60$ years & 3174 (11.5) & $3032(11.5)$ \\
\hline$<18$ years or missing & $36(0.1)$ & $\mathrm{n} / \mathrm{a}$ \\
\hline \multicolumn{3}{|l|}{ Gender } \\
\hline Male & $11,835(43.1)$ & $11,235(42.5)$ \\
\hline Female & $15,655(57.0)$ & $15,234(57.6)$ \\
\hline Missing & $0(0.0)$ & $\mathrm{n} / \mathrm{a}$ \\
\hline \multicolumn{3}{|l|}{ Population group classification } \\
\hline 'African’ & $23,059(83.9)$ & $22,202(83.9)$ \\
\hline 'Coloured' & $894(3.3)$ & $886(3.4)$ \\
\hline ‘Asian/Indian’ & $501(1.8)$ & $487(1.8)$ \\
\hline 'White' & $2926(10.6)$ & $2894(10.9)$ \\
\hline Missing & $110(0.4)$ & $\mathrm{n} / \mathrm{a}$ \\
\hline \multicolumn{3}{|l|}{ Educational attainment } \\
\hline Primary and below & $4016(14.6)$ & $3856(14.6)$ \\
\hline Secondary and above & $23,142(84.1)$ & $22,613(85.4)$ \\
\hline Missing & $332(1.2)$ & $\mathrm{n} / \mathrm{a}$ \\
\hline \multicolumn{3}{|l|}{ Employment status } \\
\hline Employed & $11,675(42.5)$ & $11,209(42.4)$ \\
\hline Unemployed & $15,815(57.5)$ & $15,260(57.7)$ \\
\hline Missing & $0(0.0)$ & $\mathrm{n} / \mathrm{a}$ \\
\hline \multicolumn{3}{|l|}{ Household-level characteristics } \\
\hline \multicolumn{3}{|l|}{ Housing tenure } \\
\hline Rented & $9233(33.6)$ & $8581(32.4)$ \\
\hline Owned & $18,257(66.4)$ & $17,888(67.6)$ \\
\hline Missing & $0(0.0)$ & $\mathrm{n} / \mathrm{a}$ \\
\hline \multicolumn{3}{|l|}{ Type of dwelling } \\
\hline Formal & $22,875(83.2)$ & $22,488(85.0)$ \\
\hline Informal & $4055(14.8)$ & $3981(15.0)$ \\
\hline Missing & $560(2.0)$ & $\mathrm{n} / \mathrm{a}$ \\
\hline \multicolumn{3}{|l|}{ Household crowding } \\
\hline Least crowded & $13,789(50.2)$ & $13,241(50.0)$ \\
\hline Most crowded & $13,699(49.8)$ & $13,228(50.0)$ \\
\hline Missing & $2(<0.1)$ & $\mathrm{n} / \mathrm{a}$ \\
\hline \multicolumn{3}{|l|}{ Basic household services } \\
\hline No piped water, mains electricity and/or toilet & $4172(15.2)$ & $3829(14.5)$ \\
\hline Piped water, mains electricity and toilet & $23,318(84.8)$ & $22,640(85.5)$ \\
\hline Missing & $0(0.0)$ & $\mathrm{n} / \mathrm{a}$ \\
\hline \multicolumn{3}{|l|}{ Household television ownership } \\
\hline Television & $23,669(86.1)$ & $22,938(86.7)$ \\
\hline
\end{tabular}


Table 1 (continued)

\begin{tabular}{|c|c|c|}
\hline Sample & $\begin{array}{l}\text { All households included in the GCRO QoL-III } \\
\text { survey (regardless of missing data) } n=27,490\end{array}$ & $\begin{array}{l}\text { All households included in the GCRO } \\
\text { QoL-III survey (providing complete data) } \\
n=26,469\end{array}$ \\
\hline Characteristic & $n(\%)$ & $n(\%)$ \\
\hline No television & $3821(13.9)$ & $3531(13.3)$ \\
\hline Missing & $0(0.0)$ & $\mathrm{n} / \mathrm{a}$ \\
\hline \multicolumn{3}{|l|}{ Household bicycle ownership } \\
\hline Bicycle & $2269(8.3)$ & $2224(8.4)$ \\
\hline No bicycle & $25,221(91.8)$ & $24,245(91.6)$ \\
\hline Missing & $0(0.0)$ & $\mathrm{n} / \mathrm{a}$ \\
\hline \multicolumn{3}{|l|}{ Household car ownership } \\
\hline Car & $8874(32.3)$ & $8722(32.9)$ \\
\hline No car & $18,616(67.7)$ & $17,747(67.1)$ \\
\hline Missing & $0(0.0)$ & $\mathrm{n} / \mathrm{a}$ \\
\hline \multicolumn{3}{|l|}{ Transport-related variables } \\
\hline \multicolumn{3}{|c|}{ Mode(s) of transport used during last "trip most often made" } \\
\hline Walk & $12,215(44.4)^{\mathrm{a}}(35.7)^{\mathrm{b}}$ & $11,650(44.0)^{\mathrm{a}}(35.4)^{\mathrm{b}}$ \\
\hline Bicycle & $108(0.4)^{\mathrm{a}}(0.3)^{\mathrm{b}}$ & $105(0.4)^{\mathrm{a}}(0.3)^{\mathrm{b}}$ \\
\hline Public transport & $15,153(55.1)^{\mathrm{a}}(44.3)^{\mathrm{b}}$ & $14,497(54.8)^{\mathrm{a}}(44.2)^{\mathrm{b}}$ \\
\hline Private car/motorbike & $6612(24.1)^{\mathrm{a}}(19.3)^{\mathrm{b}}$ & $6477(24.5)^{\mathrm{a}}(19.7)^{\mathrm{b}}$ \\
\hline Other & $94(0.3)^{\mathrm{a}}(0.2)^{\mathrm{b}}$ & $90(<0.1)^{\mathrm{a}}(0.3)^{\mathrm{b}}$ \\
\hline 'No trip made'/missing & $2924(10.6)^{\mathrm{a}} \mathrm{n} / \mathrm{a}$ & $2827(10.7)^{\mathrm{a}} \mathrm{n} / \mathrm{a}$ \\
\hline \multicolumn{3}{|c|}{ Mode of transport for longest distance of last "trip most often made" } \\
\hline Walk & $3786(13.8)^{\mathrm{a}}(15.4)^{\mathrm{b}}$ & $3614(13.6)^{\mathrm{a}}(15.3)^{\mathrm{b}}$ \\
\hline Bicycle & $60(0.2)^{\mathrm{a}}(0.2)^{\mathrm{b}}$ & $59(0.2)^{\mathrm{a}}(0.2)^{\mathrm{b}}$ \\
\hline Public transport & $14,426(52.5)^{\mathrm{a}}(58.7)^{\mathrm{b}}$ & $13,806(52.2)^{\mathrm{a}}(58.4)^{\mathrm{b}}$ \\
\hline Private car/motorbike & $6207(22.6)^{\mathrm{a}}(25.3)^{\mathrm{b}}$ & $6082(23.0)^{\mathrm{a}}(25.7)^{\mathrm{b}}$ \\
\hline Other & $87(0.3)^{\mathrm{a}}(0.4)^{\mathrm{b}}$ & $81(0.3)^{\mathrm{a}}(0.3)^{\mathrm{b}}$ \\
\hline 'No trip made'/Missing & $2924(10.6) n / a$ & $2827(10.7) \mathrm{n} / \mathrm{a}$ \\
\hline \multicolumn{3}{|l|}{ "Single biggest problem" with cycling } \\
\hline "Crime" & $1948(7.1)(10.3)^{\mathrm{c}}$ & $1862(7.0)(10.2)^{\mathrm{c}}$ \\
\hline "Destination is too far" & $2623(9.5)(13.9)^{\mathrm{c}}$ & $2448(9.3)(13.4)^{\mathrm{c}}$ \\
\hline "Vehicle accident risk" & $2995(10.9)(15.9)^{\mathrm{c}}$ & $2903(11.0)(15.9)^{\mathrm{c}}$ \\
\hline "Lack of good paths" & $881(3.2)(4.7)^{\mathrm{c}}$ & $844(3.2)(4.6)^{\mathrm{c}}$ \\
\hline "It takes too long" & $682(2.5)(3.6)^{\mathrm{c}}$ & $675(2.6)(3.7)^{\mathrm{c}}$ \\
\hline "Too much effort" & $1703(6.2)(9.0)^{\mathrm{c}}$ & $1668(6.3)(9.2)^{\mathrm{c}}$ \\
\hline "Poverty status" & $390(1.4)(2.1)^{\mathrm{c}}$ & $370(1.4)(2.0)^{\mathrm{c}}$ \\
\hline "No shower at destination" & $51(0.2)(0.3)^{\mathrm{c}}$ & $50(0.2)(0.3)^{\mathrm{c}}$ \\
\hline "No lock-up facility at destination" & $55(0.2)(0.3)^{\mathrm{c}}$ & $55(0.2)(0.3)^{\mathrm{c}}$ \\
\hline "Don’t know how to cycle" & $6050(22.0)(32.0)^{\mathrm{c}}$ & $5880(22.2)(32.2)^{\mathrm{c}}$ \\
\hline "Other" & $1501(5.5)(8.0)^{\mathrm{c}}$ & $1454(5.5)(8.0)^{\mathrm{c}}$ \\
\hline "Don't know or no opinion"/Missing & $8611(31.3)$ n/a & $8260(31.2) \mathrm{n} / \mathrm{a}$ \\
\hline
\end{tabular}

${ }^{a}$ Since responses could include more than one mode of transport, the percentages for this variable exceed $100 \%$

' The second figure in parentheses comprise the percentages of only those $n=23,642$ respondents who reported that they had made a 'trip' in the past month

${ }^{\mathrm{c}}$ The second figure in parentheses comprise the percentages of only those $n=18,209$ who cited a specific "problem" (i.e. after excluding the $n=8260$ respondents who reported "Don't know or no opinion") 


\section{Results}

\section{Demographic, Socioeconomic and Transport-Related Variation Amongst QoL-III Respondents}

Of the $n=27,490$ respondents included in the GCRO QoLIII survey [18], $n=26,469$ had complete data on all of the variables examined in the present study. By comparing the distribution of the household- and individual-level characteristics of these two samples, it was clear that these were very similar (see Table 1), suggesting that respondents with complete data were likely to be broadly representative of those included in the QoL-III survey. In both samples around two-thirds of the households were resident-owned, and over $80 \%$ were considered 'formal' dwellings, had access to all three basic services (piped water, mains electricity and one or more toilets), and owned a television. However, only around a third of households owned a car, and fewer than $10 \%$ owned a bicycle.

Given the limited availability of private transport, it is perhaps not surprising that public transport and walking were the commonest modes of transport routinely used by respondents; and while only a fifth mentioned private motorised transport, fewer than $1 \%$ reported travelling by bicycle. Likewise, when respondents were asked to select the mode of transport used to complete the "longest part" of the 'trip most often made', more than half cited public transport and around a quarter used private motor vehicles, with only $15 \%$ of these distances involving walking and fewer than $1 \%$ involving cycling. However, these figures mask the differential use of bicycles and cars during such 'trips' by respondents living in households that owned these assets. In particular, while only $n=67$ of the $n=2096(3.2 \%)$ respondents whose households owned a bicycle mentioned cycling as a "type of transport" used in these trips; $n=5787$ of the $n=8254(70.1 \%)$ whose households owned a car mentioned being the driver or passenger of a car for all or part of such trips.

The differential use of cars and bicycles for 'trips most often made' by respondents living in households that owned either of these, indicates that: in households where these were owned, cars were far more frequently used for such trips than bicycles; and, in households that owned both, cars were likely to have been used in preference to bicycles. As such, when respondents were asked to state (what they considered to be) "the single biggest problem with... cycling" it is worth bearing in mind that while the vast majority of respondents had little (if any) first-hand experience of cyclebased transport, even those who lived in households that owned a bicycle were very unlikely to have reported using this for the 'trips most often made'.
The "problem(s)... with cycling" cited by QoL-III respondents are therefore more likely to provide insights into 'attitudinal' than 'experiential' barriers to cycling (not least amongst the vast majority whose households did not own a bicycle, though also those whose households owned both a bicycle and a car, who were more likely to travel by car in preference to cycling). With this in mind it is unsurprising (though no less striking) that by far the commonest "problem" cited in the QoL-III survey was "Don't know how to cycle"- an answer given by $n=5880$ respondents (almost a third of the $n=18,209$ who cited a specific "problem"; see Table 1). In comparison, only around half as many cited "Vehicle accident risk", with fewer still citing "Destination is too far", "Crime", "Too much effort" and "Lack of good [cycle] paths", in that order. Moreover, the lack of washing facilities and somewhere to lock-up a bicycle at the trip's destination were cited by fewer than $1 \%$ of respondents, though "Poverty" and "It takes too long" were marginally more common (being cited by $1.5 \%$ and $2.7 \%$ of those who cited a specific "problem", respectively).

Unfortunately, a substantial weakness of the data generated by this item within the QoL-III survey is that multiple answers were not permitted. It is, therefore, not possible, for example, to determine the total numbers of respondents who did not know how to ride a bicycle, or who felt that "poverty" prevented them from obtaining (and/or using/ maintaining) a bicycle. For this reason, these data make it more challenging to speculate concerning the key barriers to cycling as a form of transport and to assess, for example, whether the limited numbers of households owning a bicycle was the result of: socioeconomic factors (i.e. inadequate financial resources); a decision based on the limited utility of cycling (as a suitable form of transport for the "trip most often made'); or a lack of exposure to/experience of cycling (and therefore limited, if any, cycling competency).

\section{Area-, Household- and Individual-Level Variation in Bicycle and Car Ownership}

To further explore possible explanations for the small numbers of households owning bicycles, it was necessary to examine individual-, household- and municipality-level variation in bicycle and car ownership (see Table 2). These analyses indicate that the distribution of both these assets amongst households included in the QoL-III survey was very similar. Both were less common amongst households where the key respondents were young $(<35$ years), though bicycle ownership then declined with age while car ownership did not. Both were also less common in households where the key respondent was female than where these were male; and both were strongly associated with the population group classification of the key respondent, each being far more common in households where the key respondent was 
Table 2 Individual-, household- and municipality-level variation in bicycle and car ownership amongst households included in the GCRO QoLIII survey (2013)

Bicycle ownership

$n(\%)$

Demographic characteristic

Age category

$18-25$ years

26-35 years

$36-45$ years

46-60 years

$>60$ years

Gender

Male

Female

Population group classification

'African'

'Coloured'

'Asian/Indian'

'White'

Educational attainment

Primary and below

Secondary and above

Employment status

Employed

Unemployed

Household-level characteristics

Housing tenure

Rented

Owned

Type of dwelling

Formal

Informal

Household crowding

Least crowded

Most crowded

Basic household services

No piped water, mains electricity and/or toilet

Piped water, mains electricity and toilet

Household television ownership

Television

No television

Household car ownership

Car

No car

Household bicycle ownership

Bicycle

No bicycle

Municipality

Midvaal

Mogale City

Lesedi

Randfontein
$432(8.1)$

547 (7.6)

$583(10.5)$

457 (8.6)

$205(6.8) \chi^{2}=49 ; d f=4 ; p<0.001$

1132 (10.1)

$1092(7.2) \chi^{2}=159 ; d f=1 ; p<0.001$

$1223(5.5)$

95 (10.7)

96 (19.7)

$810(28.0) \chi^{2}=1800 ; d f=3 ; p<0.001$

163 (4.2)

$2061(9.1) \chi^{2}=102 ; d f=1 ; p<0.001$

970 (6.4)

$1,254(11.2) \chi^{2}=196 ; d f=1 ; p<0.001$

413 (4.8)

$1811(10.1) \chi^{2}=212 ; d f=1 ; p<0.001$

2047 (9.1)

$177(4.5) \chi^{2}=95 ; d f=1 ; p<0.001$

1411 (10.7)

$813(6.2) \chi^{2}=175 ; d f=1 ; p<0.001$

227 (5.9)

$1997(8.8) \chi^{2}=36 ; d f=1 ; p<0.001$

2086 (9.1)

138 (3.9) $\chi^{2}=107 ; d f=1 ; p<0.001$

1689 (19.4)

$535(3.0) \chi^{2}=2100 ; d f=1 ; p<0.001$

$-$

$62(15.5)$

$110(10.7)$

39 (10.2)

$72(10.5)$
Car ownership

$n(\%)$

1420 (26.6)

2119 (29.4)

2041 (36.7)

1945 (36.4

$1197(39.5) \chi^{2}=260 ; d f=4 ; p<0.001$

4216 (37.5)

$4506(29.6) \chi^{2}=184 ; d f=1 ; p<0.001$

5237 (23.6)

409 (46.2)

408 (83.8)

$2668(92.2) \chi^{2}=6100 ; d f=3 ; p<0.001$

478 (12.4)

$8244(36.5) \chi^{2}=551 ; d f=1 ; p<0.001$

$4141(27.1)$

$4581(40.9) \chi^{2}=551 ; d f=1 ; p<0.001$

1903 (22.2)

$6819(38.1) \chi^{2}=667 ; d f=1 ; p<0.001$

8490 (37.8)

$232(5.8) \chi^{2}=1600 ; d f=1 ; p<0.001$

5683 (42.9)

$3039(23.0) \chi^{2}=1200 ; d f=1 ; p<0.001$

$350(9.1)$

$8372(37.0) \chi^{2}=1100 ; d f=1 ; p<0.001$

8537 (37.2)

$185(5.2) \chi^{2}=1400 ; d f=1 ; p<0.001$

$-$

1689 (75.9)

$7033(29.0) \chi^{2}=2000 ; d f=1 ; p<0.001$

$150(37.5)$

368 (35.7)

$135(35.2)$

$200(29.3)$ 
Table 2 (continued)

\begin{tabular}{lll}
\hline & $\begin{array}{l}\text { Bicycle ownership } \\
n(\%)\end{array}$ & $\begin{array}{l}\text { Car ownership } \\
(\%)\end{array}$ \\
\hline Emfuleni & $137(9.8)$ & $403(28.9)$ \\
Merafong City & $75(9.8)$ & $232(30.5)$ \\
City of Tshwane & $609(9.4)$ & $2254(34.7)$ \\
Westonaria & $40(8.9)$ & $111(24.6)$ \\
Ekurhuleni & $502(8.0)$ & $2012(32.1)$ \\
City of Johannesburg & $578(6.7) \chi^{2}=85 ; d f=9 ; p<0.001$ & $2857(33.2) \chi^{2}=51 ; d f=9 ; p<0.001$ \\
\hline
\end{tabular}

All results are presented as frequencies with percentages in parentheses (\%). The statistical precision of differences in the distribution of bicycle and car ownership associated with each of the characteristics examined was assessed using Pearson's Chi-squared

classified as 'White' than in those where the key respondent was classified as 'Asian/Indian', 'Coloured' or 'African' (in that order). Key respondents with at least some secondary education, and those who were employed, were also more likely to report that their household owned both a bicycle and a car. Thereafter, all of the household-level markers of socioeconomic position (i.e. housing tenure, type of dwelling, crowding, access to basic services and TV ownership) were all more favourable amongst households owning bicycles and/or cars; and ownership of either was positively associated with ownership of the other (see Table 2). Finally, analysis of households sampled in each of the ten Gauteng municipalities revealed there was also substantial variation in the ownership of bicycles and cars therein, though with far greater variation in the rates of bicycle ownership (which ranged from 6.7 to $15.5 \%$ ) than in the rates of car ownership (24.6-37.5\%). Moreover, while three of the four municipalities with the highest rates of bicycle ownership also had the highest rates of car ownership, the municipality with the lowest rate of bicycle ownership (the City of Johannesburg: $6.7 \%$ ) had the fifth highest rate of car ownership (33.2\%). Thus, while individual- and household-level characteristics suggest that bicycle and car ownership was more common amongst wealthier, economically active households, the contrasting distribution of these assets across households in different municipalities suggests that other factors (such as the availability of public transport, or the proximity of employment, retail and recreation facilities) also play a role in the utility of owning bicycles and/or cars.

Whilst most of the individual- and household-level demographic and socioeconomic relationships with bicycle and car ownership were attenuated following adjustment for measured potential confounding, the precision of all but three (age, type of dwelling and household services; though for bicycle ownership alone) remained strong (see Table 3). However, all of these relationships were weaker for bicycle ownership than for car ownership, suggesting that demographic and socioeconomic factors are weaker predictors (and determinants) of owning a bicycle than of owning a car. This may also reflect greater heterogeneity in the functional significance of bicycle ownership, i.e. whether as an asset owned primarily for recreational purposes (which is likely to be the case for many of the wealthier households that also owned cars) or as a form of transport (for poorer households in which bicycles were the only form of private transport). Indeed, of particular interest in this regard were the very different odds of car ownership amongst those aged $>60$ years before and after adjustment for gender and population group classification. Following adjustment, the odds of car ownership changed from 1.80 (95\% CI 1.64, 1.98) to 0.88 (95\% CI $0.79,1.99)$, suggesting very different patterns of car ownership by gender and/or population group. Notably, a similar effect was not observed for bicycle ownership amongst any of the age groups examined following adjustment for gender and population group classification (see Table 3). These issues aside, the multivariable analyses summarised in Table 3 largely confirm that bicycles and cars are predominantly possessions of households where the key respondents were 'White', middle aged, middle-class men; and that, as such, the ownership of both bicycles and cars appear not only attributes of, but also markers for, wealthier households.

Finally, to establish whether the perceived barriers to cycling were determined simply by bicycle or car ownership, or were also patterned according to demographic and socioeconomic factors, additional multivariable analyses were conducted for each of the six most commonly cited "single biggest problem[s] with... cycling": "Don't know how to cycle"; "Vehicle accident risk"; "Destination is too far"; "Crime"; "Too much effort"; and "Lack of good paths". This involved a series of logistic regression analyses that compared the odds of respondents with different individual- and household-level characteristics citing each of these six "problems" as compared to any of the others (excluding respondents who responded "Don't know or no opinion"). Table 4 summarises the results of these analyses, both before and after adjusting for measured potential confounders, as identified using the DAG (see Fig. 1). Unlike 
Table 3 Individual- and household-level demographic and socioeconomic determinants of bicycle and car ownership, before and after adjustment for potential confounders

\begin{tabular}{|c|c|c|c|c|}
\hline \multirow{3}{*}{$\begin{array}{l}\text { Sample } \\
\text { Covariates (referent) }\end{array}$} & \multicolumn{2}{|l|}{ Bicycle ownership } & \multicolumn{2}{|l|}{ Car ownership } \\
\hline & Unadjusted & Adjusted $^{\mathrm{a}, \mathrm{b}, \mathrm{c}}$ & Unadjusted & Adjusted $^{\mathrm{a}, \mathrm{b}, \mathrm{c}}$ \\
\hline & OR $(95 \% \mathrm{CI})$ & OR $(95 \%$ CI $)$ & OR $(95 \%$ CI $)$ & OR $(95 \%$ CI $)$ \\
\hline \multicolumn{5}{|l|}{ Age $(18-25 \text { years })^{\mathrm{a}}$} \\
\hline $26-35$ years & $0.93(0.82,1.06)$ & $0.90(0.79,1.04)$ & $1.15(1.06,1.24)$ & $1.14(1.05,1.25)$ \\
\hline $36-45$ years & $1.33(1.16,1.51)$ & $1.07(0.93,1.22)$ & $1.60(1.47,1.73)$ & $1.35(1.24,1.48)$ \\
\hline $46-60$ years & $1.06(0.93,1.22)$ & $0.77(0.67,0.90)$ & $1.58(1.46,1.72)$ & $1.24(1.13,1.36)$ \\
\hline$>60$ years & $0.82(0.69,0.98)$ & $0.42(0.35,0.50)$ & $1.80(1.64,1.98)$ & $0.89(0.79,1.00)$ \\
\hline \multicolumn{5}{|l|}{ 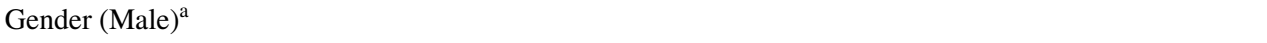 } \\
\hline Female & $0.69(0.63,0.75)$ & $0.77(0.71,0.85)$ & $0.72(0.69,0.76)$ & $0.75(0.71,0.80)$ \\
\hline \multicolumn{5}{|c|}{ Population group classification ('White') ${ }^{\mathrm{a}}$} \\
\hline 'African' & $0.15(0.14,0.17)$ & $0.13(0.12,0.15)$ & $0.03(0.02,0.03)$ & $0.03(0.02,0.03)$ \\
\hline 'Coloured' & $0.31(0.25,0.39)$ & $0.27(0.22,0.35)$ & $0.07(0.06,0.09)$ & $0.07(0.06,0.09)$ \\
\hline 'Asian/Indian' & $0.63(0.50,0.80)$ & $0.56(0.44,0.71)$ & $0.44(0.33,0.58)$ & $0.42(0.31,0.55)$ \\
\hline \multicolumn{5}{|c|}{ Educational attainment (primary or less) } \\
\hline Secondary or more & $2.27(1.93,2.68)$ & $1.19(1.00,1.42)$ & $4.05(3.67,4.48)$ & $3.12(2.80,3.49)$ \\
\hline \multicolumn{5}{|c|}{ Employment status (unemployed) } \\
\hline Employed & $1.86(1.70,2.03)$ & $1.49(1.35,1.65)$ & $1.86(1.76,1.95)$ & $1.73(1.62,1.84)$ \\
\hline \multicolumn{5}{|l|}{ Housing tenure (rented) ${ }^{\mathrm{b}}$} \\
\hline Owned & $2.23(2.00,2.49)$ & $2.10(1.87,2.36)$ & $2.16(2.04,2.29)$ & $2.23(2.08,2.39)$ \\
\hline \multicolumn{5}{|l|}{ Type of dwelling (informal) ${ }^{b}$} \\
\hline Formal & $2.15(1.84,2.52)$ & $1.35(1.15,1.59)$ & $9.80(8.56,11.22)$ & $5.96(5.19,6.85)$ \\
\hline \multicolumn{5}{|c|}{ Household crowding (most crowded half) ${ }^{b}$} \\
\hline Least crowded half & $1.82(1.66,1.99)$ & $1.16(1.05,1.28)$ & $2.52(2.39,2.66)$ & $1.58(1.48,1.68)$ \\
\hline \multicolumn{5}{|c|}{ Household services (no piped water, mains electricity and/or toilet) ${ }^{\mathrm{b}}$} \\
\hline Water, electricity and toilet & $1.54(1.33,1.77)$ & $1.10(0.95,1.28)$ & $5.83(5.21,6.53)$ & $4.81(4.24,5.46)$ \\
\hline \multicolumn{5}{|c|}{ Television ownership (no television) ${ }^{\mathrm{c}}$} \\
\hline Television & $2.46(2.06,2.93)$ & $1.74(1.42,2.13)$ & $10.72(9.22,12.46)$ & $5.53(4.64,6.58)$ \\
\hline \multicolumn{5}{|l|}{ Bicycle ownership (no bicycle) ${ }^{c}$} \\
\hline Bicycle & & & $7.73(6.98,8.55)$ & $5.15(4.55,5.83)$ \\
\hline \multicolumn{5}{|l|}{ Car ownership (no car) ${ }^{\mathrm{c}}$} \\
\hline Car & $7.73(6.98,8.55)$ & $5.17(4.58,5.85)$ & & \\
\hline
\end{tabular}

All results are presented as odds ratios (ORs) with 95\% confidence intervals (95\% CIs) in parentheses

${ }^{a}$ Age, population group classification and gender were entered simultaneously into the confounder-adjusted models (i.e. after adjusting for one another)

${ }^{b}$ Housing tenure, type of dwelling, household crowding and basic household services were entered separately into the confounder-adjusted models (after adjusting for all preceding variables)

${ }^{c}$ Household television, bicycle and car ownership were entered separately into the confounder-adjusted models (after adjusting for all preceding variables) the analysis of bicycle and car ownership (summarised in Table 3), Table 4 revealed that the six commonest "problems" were associated with very different demographic and socioeconomic characteristics of the key respondents and their households. In particular, older respondents were more likely to cite "Don't know how" than any of the other five common "problems", as were women and those classified as 'African', 'Asian/Indian' and 'Coloured' (in that order). In contrast, respondents with either some secondary education and/or employment were more likely to cite "Vehicle accident risk", "Crime" and "Destination too far". Respondents living in formal dwellings and in households that were least crowded and/or better serviced were also more likely to cite "Vehicle accident risk", although they also cited "Too much effort", and both of these were also the principal "problem" cited by those whose households owned a television. Somewhat unsurprisingly, respondents whose households owned a bicycle were far less likely to cite "Don't know how" as the principal "problem", and while these respondents were more likely to cite "Crime" and "Too much effort", bicycle ownership was also the only variable associated with citing "Lack of good paths" as the principal "problem" facing 
Table 4 Demographic and socioeconomic determinants of perceived "problems with... cycling" in Gauteng, before and after adjustment for potential confounders

Covariate (referent) "What is the single biggest problem with cycling to work, the shops or anywhere, not for exercise (even if you do not cycle)"-Referent: Other answers (excluding "Don't know, no opinion")

\begin{tabular}{|c|c|c|c|c|c|c|}
\hline & \multicolumn{2}{|l|}{ Don't know how } & \multicolumn{2}{|c|}{ Vehicle accident risk } & \multicolumn{2}{|l|}{ Destination too far } \\
\hline & Unadjusted & Adjusted $^{\mathrm{a}, \mathrm{b}, \mathrm{c}}$ & Unadjusted & Adjusted $^{a, b, c}$ & Unadjusted & Adjusted $^{\mathrm{a}, \mathrm{b}, \mathrm{c}}$ \\
\hline & OR $(95 \% \mathrm{CI})$ & OR $(95 \% \mathrm{CI})$ & OR $(95 \% \mathrm{CI})$ & OR $(95 \% \mathrm{CI})$ & OR $(95 \% \mathrm{CI})$ & OR $(95 \% \mathrm{CI})$ \\
\hline \multicolumn{7}{|l|}{ Age category $(18-25)^{\mathrm{a}}$} \\
\hline 26-35 years & $1.03(0.94,1.13)$ & $1.03(0.94,1.14)$ & $1.02(0.91,1.15)$ & $1.02(0.91,1.15)$ & $0.97(0.86,1.10)$ & $0.97(0.86,1.10)$ \\
\hline $36-45$ years & $1.16(1.05,1.28)$ & $1.22(1.10,1.35)$ & $1.03(0.91,1.16)$ & $0.99(0.88,1.12)$ & $0.97(0.85,1.11)$ & $0.97(0.85,1.10)$ \\
\hline $46-60$ years & $1.35(1.22,1.49)$ & $1.43(1.29,1.58)$ & $0.93(0.82,1.06)$ & $0.89(0.78,1.01)$ & $0.92(0.80,1.05)$ & $0.91(0.80,1.04)$ \\
\hline$>60$ years & $1.65(1.48,1.85)$ & $1.97(1.75,2.22)$ & $0.88(0.75,1.02)$ & $0.77(0.66,0.90)$ & $0.72(0.61,0.86)$ & $0.71(0.60,0.85)$ \\
\hline \multicolumn{7}{|l|}{ Gender (male) ${ }^{1}$} \\
\hline Female & $2.43(2.27,2.60)$ & $2.36(2.20,2.52)$ & $0.74(0.69,0.80)$ & $0.76(0.71,0.83)$ & $0.81(0.74,0.88)$ & $0.82(0.75,0.89)$ \\
\hline \multicolumn{7}{|c|}{ Population group classification ('White') ${ }^{\mathrm{a}}$} \\
\hline 'African' & $2.74(2.42,3.11)$ & $3.05(2.67,3.47)$ & $0.56(0.50,0.63)$ & $0.54(0.48,0.61)$ & $0.91(0.79,1.04)$ & $0.87(0.76,1.00)$ \\
\hline 'Coloured' & $1.91(1.54,2.36)$ & $1.99(1.59,2.48)$ & $0.66(0.52,0.83)$ & $0.65(0.51,0.82)$ & $0.81(0.61,1.06)$ & $0.79(0.60,1.03)$ \\
\hline 'Asian/Indian’ & $2.25(1.72,2.95)$ & $2.60(1.97,3.43)$ & $0.69(0.51,0.94)$ & $0.66(0.49,0.90)$ & $0.86(0.60,1.22)$ & $0.82(0.57,1.17)$ \\
\hline \multicolumn{7}{|c|}{ Educational attainment (primary or less) } \\
\hline Secondary or more & $0.66(0.60,0.71)$ & $0.95(0.87,1.05)$ & $1.35(1.20,1.53)$ & $1.14(0.99,1.30)$ & $1.23(1.08,1.40)$ & $1.12(0.97,1.29)$ \\
\hline \multicolumn{7}{|c|}{ Employment (unemployed) } \\
\hline Employed & $0.70(0.66,0.75)$ & $0.86(0.80,0.92)$ & $1.27(1.17,1.37)$ & $1.15(1.06,1.26)$ & $1.27(1.17,1.39)$ & $1.21(1.10,1.33)$ \\
\hline \multicolumn{7}{|c|}{ Housing tenure (rented $)^{\mathrm{b}}$} \\
\hline Owned & $1.19(1.11,1.27)$ & $1.12(1.04,1.20)$ & $0.78(0.72,0.85)$ & $0.78(0.71,0.85)$ & $1.08(0.99,1.19)$ & $1.15(1.04,1.26)$ \\
\hline \multicolumn{7}{|c|}{ Type of dwelling type (informal) ${ }^{b}$} \\
\hline Formal & $0.94(0.87,1.03)$ & $1.01(0.92,1.11)$ & $1.26(1.12,1.41)$ & $1.16(1.03,1.31)$ & $0.91(0.80,1.01)$ & $0.89(0.78,1.00)$ \\
\hline \multicolumn{7}{|c|}{ Household crowding (most crowded half) ${ }^{\mathrm{b}}$} \\
\hline Least crowded half & $0.77(0.72,0.82)$ & $0.95(0.89,1.02)$ & $1.21(1.12,1.31)$ & $1.05(0.97,1.15)$ & $1.14(1.05,1.25)$ & $1.10(1.00,1.20)$ \\
\hline \multicolumn{7}{|c|}{ Basic household services (no piped water, mains electricity and/or toilet) ${ }^{\mathrm{b}}$} \\
\hline All three services & $1.09(1.00,1.20)$ & $1.16(1.06,1.27)$ & $1.26(1.12,1.42)$ & $1.19(1.06,1.35)$ & $0.83(0.74,0.93)$ & $0.82(0.73,0.93)$ \\
\hline \multicolumn{7}{|c|}{ Household television ownership (no television) ${ }^{c}$} \\
\hline Television & $1.03(0.94,1.13)$ & $1.01(0.90,1.14)$ & $1.21(1.06,1.37)$ & $1.04(0.90,1.21)$ & $0.95(0.84,1.08)$ & $1.07(0.92,1.25)$ \\
\hline \multicolumn{7}{|c|}{ Household bicycle ownership (no bicycle) ${ }^{c}$} \\
\hline Bicycle & $0.47(0.41,0.54)$ & $0.63(0.55,0.72)$ & $1.14(1.00,1.31)$ & $0.93(0.80,1.07)$ & $1.14(0.99,1.32)$ & $1.04(0.89,1.22)$ \\
\hline \multicolumn{7}{|c|}{ Household car ownership (no car) ${ }^{c}$} \\
\hline Car & $0.72(0.67,0.77)$ & $0.98(0.91,1.07)$ & $1.31(1.20,1.42)$ & $1.06(0.96,1.17)$ & $1.09(1.00,1.19)$ & $1.03(0.93,1.15)$ \\
\hline \multirow[t]{3}{*}{ Covariate (referent) } & \multicolumn{2}{|l|}{ Crime } & \multicolumn{2}{|l|}{ Too much effort } & \multicolumn{2}{|l|}{ Lack of good paths } \\
\hline & Unadjusted & Adjusted $^{\mathrm{a}, \mathrm{b}, \mathrm{c}}$ & Unadjusted & Adjusted $^{a, b, c}$ & Unadjusted & Adjusted $^{\mathrm{a}, \mathrm{b}, \mathrm{c}}$ \\
\hline & OR $(95 \% \mathrm{CI})$ & OR $(95 \% \mathrm{CI})$ & OR $(95 \% \mathrm{CI})$ & OR $(95 \% \mathrm{CI})$ & OR $(95 \% \mathrm{CI})$ & OR $(95 \% \mathrm{CI})$ \\
\hline \multicolumn{7}{|l|}{ Age category $(18-25)^{\mathrm{a}}$} \\
\hline $26-35$ years & $0.85(0.74,0.98)$ & $0.85(0.74,0.98)$ & $0.94(0.81,1.08)$ & $0.94(0.81,1.08)$ & $0.97(0.80,1.18)$ & $0.97(0.80,1.18)$ \\
\hline $36-45$ years & $0.89(0.77,1.03)$ & $0.86(0.75,1.00)$ & $0.81(0.70,0.95)$ & $0.80(0.68,0.93)$ & $0.86(0.70,1.06)$ & $0.87(0.71,1.08)$ \\
\hline $46-60$ years & $0.86(0.74,1.00)$ & $0.83(0.71,0.96)$ & $0.95(0.81,1.11)$ & $0.92(0.79,1.08)$ & $0.82(0.66,1.01)$ & $0.84(0.67,1.04)$ \\
\hline$>60$ years & $0.81(0.67,0.96)$ & $0.74(0.62,0.89)$ & $0.98(0.81,1.17)$ & $0.91(0.75,1.10)$ & $0.57(0.42,0.76)$ & $0.59(0.44,0.79)$ \\
\hline Gender $(\text { male })^{1}$ & & & & & & \\
\hline Female & $0.89(0.81,0.98)$ & $0.91(0.83,1.01)$ & $0.67(0.60,0.74)$ & $0.68(0.61,0.75)$ & $0.68(0.59,0.78)$ & $1.02(0.87,1.18)$ \\
\hline Population group clas & ification ('White') ${ }^{a}$ & & & & & \\
\hline ‘African’ & $0.72(0.62,0.83)$ & $0.69(0.60,0.81)$ & $0.65(0.56,0.75)$ & $0.66(0.57,0.77)$ & $1.12(0.88,1.41)$ & $1.19(0.92,1.55)$ \\
\hline 'Coloured' & $1.49(1.17,1.91)$ & $1.45(1.13,1.86)$ & $0.56(0.40,0.77)$ & $0.57(0.41,0.80)$ & $0.78(0.48,1.27)$ & $0.76(0.45,1.29)$ \\
\hline 'Asian/Indian' & $1.36(0.98,1.89)$ & $1.33(0.96,1.84)$ & $0.83(0.57,1.21)$ & $0.82(0.56,1.20)$ & $0.73(0.38,1.43)$ & $1.32(0.61,2.84)$ \\
\hline
\end{tabular}


Table 4 (continued)

\begin{tabular}{|c|c|c|c|c|c|c|}
\hline \multirow[t]{3}{*}{ Covariate (referent) } & \multicolumn{2}{|l|}{ Crime } & \multicolumn{2}{|l|}{ Too much effort } & \multicolumn{2}{|c|}{ Lack of good paths } \\
\hline & Unadjusted & Adjusted $^{\mathrm{a}, \mathrm{b}, \mathrm{c}}$ & Unadjusted & Adjusted $^{\mathrm{a}, \mathrm{b}, \mathrm{c}}$ & Unadjusted & Adjusted $^{\mathrm{a}, \mathrm{b}, \mathrm{c}}$ \\
\hline & OR $(95 \% \mathrm{CI})$ & OR $(95 \% \mathrm{CI})$ & OR $(95 \% \mathrm{CI})$ & OR $(95 \% \mathrm{CI})$ & OR $(95 \% \mathrm{CI})$ & OR $(95 \% \mathrm{CI})$ \\
\hline \multicolumn{7}{|c|}{ Educational attainment (primary or less) } \\
\hline Secondary or more & $1.35(1.16,1.56)$ & $1.19(1.01,1.41)$ & $1.06(0.91,1.22)$ & $0.94(0.80,1.11)$ & $1.11(0.90,1.36)$ & $0.95(0.76,1.18)$ \\
\hline \multicolumn{7}{|c|}{ Employment (unemployed) } \\
\hline Employed & $1.06(0.96,1.17)$ & $1.04(0.93,1.15)$ & $1.05(0.95,1.17)$ & $0.98(0.87,1.09)$ & $0.98(0.85,1.13)$ & $0.87(0.75,1.01)$ \\
\hline \multicolumn{7}{|c|}{ Housing tenure (rented) $)^{2}$} \\
\hline Owned & $1.00(0.90,1.11)$ & $0.99(0.89,1.10)$ & $1.00(0.89,1.11)$ & $0.98(0.88,1.10)$ & $1.25(1.08,1.46)$ & $1.34(1.15,1.57)$ \\
\hline \multicolumn{7}{|c|}{ Type of dwelling (informal) ${ }^{2}$} \\
\hline Formal & $1.21(1.05,1.40)$ & $1.12(0.97,1.29)$ & $1.31(1.12,1.52)$ & $1.25(1.07,1.47)$ & $0.49(0.42,0.57)$ & $0.50(0.42,0.59)$ \\
\hline \multicolumn{7}{|c|}{ Household crowding (most crowded half) ${ }^{b}$} \\
\hline Least crowded half & $0.93(0.85,1.02)$ & $0.86(0.77,0.95)$ & $1.19(1.07,1.31)$ & $1.05(0.95,1.18)$ & $0.92(0.80,1.05)$ & $0.91(0.79,1.06)$ \\
\hline \multicolumn{7}{|c|}{ Basic household services (no piped water, mains electricity and/or toilet) ${ }^{b}$} \\
\hline All three services & $1.01(0.88,1.15)$ & $0.93(0.81,1.06)$ & $1.33(1.14,1.55)$ & $1.30(1.11,1.52)$ & $0.47(0.40,0.55)$ & $0.48(0.41,0.57)$ \\
\hline \multicolumn{7}{|c|}{ Household television ownership (no television) ${ }^{\mathrm{c}}$} \\
\hline Television & $0.86(0.75,0.99)$ & $0.73(0.62,0.86)$ & $1.62(1.35,1.94)$ & $1.54(1.26,1.90)$ & $0.60(0.50,0.71)$ & $1.01(0.81,1.26)$ \\
\hline \multicolumn{7}{|c|}{ Household bicycle ownership (no bicycle) ${ }^{c}$} \\
\hline Bicycle & $1.53(1.32,1.78)$ & $1.38(1.17,1.62)$ & $1.39(1.18,1.63)$ & $1.21(1.02,1.44)$ & $1.63(1.32,2.01)$ & $1.68(1.35,2.10)$ \\
\hline \multicolumn{7}{|c|}{ Household car ownership (no car) ${ }^{c}$} \\
\hline Car & $1.12(1.01,1.24)$ & $0.94(0.83,1.06)$ & $1.45(1.31,1.61)$ & $1.32(1.16,1.49)$ & $0.77(0.66,0.91)$ & $0.84(0.69,1.01)$ \\
\hline
\end{tabular}

${ }^{a}$ Age, population group classification and gender were entered simultaneously into the confounder-adjusted models (i.e. after adjusting for one another)

${ }^{b}$ Housing tenure, type of dwelling, household crowding and basic household services were entered separately into the confounder-adjusted models (after adjusting for all preceding variables)

${ }^{c}$ Household television, bicycle and car ownership were entered separately into the confounder-adjusted models (after adjusting for all preceding variables)

cycling as a means of transport. In contrast, respondents living in households that owned cars primarily cited only "Too much effort" as the "biggest problem with... cycling".

These, somewhat complicated relationships nonetheless reveal four distinct patterns associated with: cycling competency, fear (of accidents and/or crime), practicability (distance and effort) and infrastructure (cycle paths). Each of these displayed fairly clear trends with demographic and socioeconomic factors, and with access to/ownership of private transport (whether a bicycle and/or a car). Interpreting these as potential limiting factors for cycle-based transport, cycling competency appeared least relevant to younger, male respondents classified as 'White'; presumably because this demographic group is most likely to have learnt how to ride a bicycle. Fear appears to dissuade travelling by bicycle amongst better educated, economically active respondents living in better quality and better equipped households; perhaps because their more 'comfortable' social position makes them unfamiliar with, and/ or unwilling to take, the (unnecessary) risks they associate with cycling. This might also explain why respondents from these sorts of households, like those who were better educated and economically active, appeared to be put off cycling by the (additional, unnecessary) effort involved, and the distances this might entail when, for example, commuting to work. The impracticability of cycle-based transport for longer journeys appears particularly important to those living in households that owned a car, for whom the effort required to adopt non-motorised transport (given that they owned/had access to private motor transport) appeared pre-eminent. Finally, it was particularly striking that respondents from households that owned a bicycle appeared to recognise the lack of appropriate cycle paths as a key barrier to cycling. Since these respondents had both the competency and the means required to cycle, they are perhaps best equipped to recognise the necessity of appropriate infrastructure to facilitate travelling by bicycle.

\section{Discussion}

Given that so few of the households surveyed by the QoL-III owned bicycles $(<10 \%)$, it is perhaps surprising that more respondents (rather than only around a third) did not cite "Don't know how to cycle" as the "single biggest problem 
with... cycling" as a form of transport. However, since the instrument used by the QoL-III survey only allowed respondents to provide one answer to this item, it seems very likely that many of the respondents who cited other "problem(s)" (or "Don't know or no opinion") will also have had limited (if any) cycling competency. The low prevalence of bicycle ownership and the low prevalence of cycling competency therefore appear to be the two most important structural barriers to cycle-based transport in Gauteng. Both are likely to play a large part in the very small number of respondents (just $0.3 \%$ ) who included cycling as one of the modes of transport used in the 'trips most often made', and the even smaller number who reported cycling for the longest part of these trips $(0.2 \%$; see Table 1$)$. Nonetheless, these figures may also reflect substantial, additional attitudinal barriers regarding the perceived utility of cycling for many such trips (not least where these involve travelling longer distances, over hilly terrain and/or transporting goods or people); accentuated by commonly held perceptions of the effort required and the risks involved [13]. These attitudinal barriers are harder to discern from the data available from the QoL-III survey, although these are evident from the distribution and use of private vehicles (both bicycles and cars), and from demographic and socioeconomic variation in the "single biggest problem(s) with... cycling" cited by survey respondents.

In terms of the distribution of private vehicle ownership, the QoL-III survey data reveal that a far larger proportion of Gauteng's households owns cars (>30\%) than bicycles $(<10 \%)$, and that bicycles are predominantly owned by the wealthier households that also own cars $(>75 \%$ of car-owning households also owning bicycles). This distribution of bicycle ownership indicates that bicycles are not the only form of private transport available to (most of) the households that own them, and that bicycles may not have been purchased (solely) for transport purposes (being used instead, and primarily perhaps, for recreational purposes [12]). Indeed, this might explain the geographical variation in bicycle (and car) ownership amongst households in each of Gauteng's ten municipalities, and why some municipalities (such as the City of Johannesburg) have high rates of car ownership but low rates of bicycle ownership. If this variation in bicycle ownership reflects a tendency for more of the wealthier, car-owning households to own bicycles in those municipalities where bicycles can (more easily) be used for recreational purposes, then variation in bicycle ownership amongst households in different municipalities (together with variation in the availability of alternative forms of private and public transport in each municipality) might help to explain the very limited use of cycle-based transport for 'trips most often made' even by those households that owned bicycles. Indeed, while $>70 \%$ of respondents from car-owning households included driving a car or being a car passenger in the list of "different types of transport" used for 'trips most often made', fewer than 5\% of those from bicycle-owning households included cycling in this list. In other words, most respondents from households that owned cars reported travelling by car, while very few respondents from households owning bicycles reported travelling by bicycle.

Regardless of the reason why wealthier car-owning households also own bicycles, there remain two, ostensibly intractable, challenges facing efforts to increase the number of journeys taken by bicycle in Gauteng: first, the vast majority of households lack the means to cycle (i.e. they do not own a bicycle); and second, the vast majority of households that own a bicycle $(>75 \%)$ also own a car (i.e. they have an alternative means of private transport, and might therefore have less incentive to use cycle-based transport [2, 12]. Given the small percentage of households that own a bicycle it is perhaps unsurprising that by far the largest number of respondents chose "Don't know how to cycle" as the "single biggest problem with... cycling" ( $>30 \%$; more than twice as many as the next most popular "problem"), although this was also most commonly cited by female respondents and those classified as 'African', 'Asian/Indian' and 'Coloured' (in that order). Whilst owning a bicycle (or having access to a bicycle, as a result of living in a household that owns a bicycle) is inevitably a pre-requisite for learning how to ride a bicycle, knowing how to cycle is also likely to strengthen interest in owning a bicycle [13]. Exposure to others who own and use bicycles is also likely to play an important role in 'normalising' learning to ride, riding, and owning a bicycle $[17,35,40]$. In this regard, it may not be surprising that male respondents, and those classified as 'White', who were least likely to cite "Don't know how to ride", were also those most likely to live in households that owned a bicycle (see Table 2). Since the key respondents in these households were also more likely to be better educated and economically active, it might appear that socioeconomic factors are the principal barrier to bicycle ownership (Table 3) and, thereby, cycling competency. Yet, despite the fact that bicycle ownership was commonest amongst wealthier and better serviced households, with better educated and employed key respondents, the "problem" most likely to reflect financial barriers to bicycle ownership ("Poverty status") was actually only cited by around $2 \%$ of respondents. This is remarkable given that over $90 \%$ of respondents lived in households that did not own a bicycle. Indeed, although wealthier households were more likely to own bicycles it is far from certain how important socioeconomic factors might actually be as barriers to cycle-based transport. This is because the most commonly cited "single biggest problem(s) with... cycling" (beyond not knowing how) were: first, the perceived risks; and second, the practical challenges involved.

Three such risks comprised another $30 \%$ of responses to this question (namely, "Vehicle accident risk": 15.9\%; 
"Crime": 10.2\%; and "Lack of good paths": 4.6\%) although, arguably, the last of these might also apply to the practical challenges involved in cycling on unsuitable routes/surfaces. Concerns over such risks were more commonly cited by better educated, economically active respondents and those living in better quality/serviced households. Respondents from similar socioeconomic circumstances were also more likely to cite "problems" relevant to the impracticability of cycling (namely, "Destination is too far": 9.3\%; and "Too much effort": $6.3 \%$ ), suggesting that respondents from households that were likely to be most capable of purchasing/owning bicycles perceived cycling to be risky/dangerous and difficult and/or impracticable. Indeed, the commonest "problems" cited by respondents from the minority of households that owned a bicycle were "Lack of good paths", "Crime" and "Too much effort" (in declining order of importance)suggesting that the issues dissuading these respondents from using the bicycles their households owned were very similar to those cited by respondents whose households were unlikely to own a bicycle (yet are likely to have been able to own one if they so chose). Nonetheless, these findings do provide some comfort for the City of Johannesburg's NMT strategy [6, 8], which claims to have constructed/designated over $400 \mathrm{~km}$ of cycle lanes [47] at a reported cost of at least ZAR70Million (approximately US\$5Million at 2015 exchange rates [27]. This is because respondents who cited a "Lack of good paths" as the "single biggest problem(s) with... cycling" were primarily those from households that owned bicycles and who are therefore best placed to make greater use of cycle-based transport. In addressing this "problem" by building dedicated cycle lanes the City will have removed a key barrier for those equipped to use them. Unfortunately, as the present study has shown, substantial structural and attitudinal barriers remain (not least the limited prevalence of bicycle ownership and cycling competency, and the perception of cycling as risky, challenging and impracticable).

\section{Conclusion}

While the limited number of households owning bicycles (and the availability of cars in many of these households) might pose the most immediate barrier to cycle-based transport in Gauteng, negative attitudes towards travelling by bicycle (amongst those who have access to bicycles and those who do not) are likely to pose more persistent barriers in the longer term. Attitudes towards cycling as a potential form of transport are unlikely to change whilst those who own both bicycles and cars prefer to travel by car, and while bicycles are framed as recreational accessories (by those who own them and those who do not) rather than as credible (alternative) forms of transport. Although it might be argued that a potential benefit of the very similar distribution of bicycle and car ownership is that encouraging those who own bicycles to use them more (i.e. for transport rather than purely for recreational purposes) would lead to a reduction in the number of private motor vehicles using the roads (albeit for those 'trips' in which cycle-based transport replaced the use of a car); this would require a sea change in attitudes towards cycle-based transport, and assumes that bicycles can offer an equivalent (acceptable, desirable and practicable) form of transport for many of those households that own cars. However unlikely such a change in transport behaviour might appear, the provision of dedicated cycle lanes by the City of Johannesburg does make this possible and perhaps less fanciful [28]. Even a small increase in the visible use of cycle-based transport might help dispel some of the attitudinal barriers to cycling, and help challenge the perception of cycling as (only) a recreational pursuit (as Goodman et al. suggest occurred in London [21]).

Acknowledgements The data used in this publication are taken from the 2013 Quality of Life survey commissioned by the Gauteng CityRegion Observatory-a partnership of the University of Johannesburg, the University of the Witwatersrand, Johannesburg, and the Gauteng Provincial Government (www.gcro.ac.za).

Open Access This article is licensed under a Creative Commons Attribution 4.0 International License, which permits use, sharing, adaptation, distribution and reproduction in any medium or format, as long as you give appropriate credit to the original author(s) and the source, provide a link to the Creative Commons licence, and indicate if changes were made. The images or other third party material in this article are included in the article's Creative Commons licence, unless indicated otherwise in a credit line to the material. If material is not included in the article's Creative Commons licence and your intended use is not permitted by statutory regulation or exceeds the permitted use, you will need to obtain permission directly from the copyright holder. To view a copy of this licence, visit http://creativecommons.org/licenses/by/4.0/.

\section{References}

1. Basu S, Vasudevan V (2013) Effect of bicycle friendly roadway infrastructure on bicycling activities in urban India. Procedia Soc Behav Sci 104:1139-1148

2. Bechstein E (2010) Cycling as a supplementary mode to public transport: a case study of low income commuters in South Africa. Proc S Afr Trans Conf 29:33-41

3. Bester P (2011) An environmental analysis of cycling South Africa. Masters in Commerce Thesis; University of South Africa, pp 1-256. http://uir.unisa.ac.za/bitstream/10500/6728/1/dissertati on_\%20bester_p.pdf. Accessed Mar 2019

4. BMW (2017) Plant Rosslyn: history. https://www.bmwgroupplants.com/rosslyn/en/our-plant/history.html. Accessed Mar 2019

5. City of Johannesburg (2009) Framework for non-motorised transport. http://www.joburg-archive.co.za/2009/pdfs/transport/nmt framework09.pdf. Accessed Mar 2019

6. City of Johannesburg (2013) Strategic integrated transport plan framework for City of Johannesburg: draft for discussion. https:// 
joburg.org.za/images/stories/2013/May/CoJ\%20SITPF\%20Draft\% 2013\%20May\%202013.pdf. Accessed Mar 2019

7. City of Johannesburg (2015) Transport department: non-motorised transport. http://joburg.org.za/index.php?option=com_conte nt\&task $=$ view $\&$ id $=1226 \&$ Itemid $=78 \&$ limitstart $=4$. Accessed Mar 2019

8. City of Johannesburg (2017) Corridors of freedom for a peoplecentred city. http://www.corridorsoffreedom.co.za/. Accessed Mar 2019

9. De Geus B, Joncheere J, Meeusen R (2009) Commuter cycling: effect on physical performance in untrained men and women in Flanders: minimum dose to improve indexes of fitness. Scand J Med Sci Sport 19:179-187

10. DeMaio P (2009) Bike-sharing: history, impacts, models of provision, and future. J Publ Trans 12:41-56

11. Department of Transport (2008) Draft national non-motorised transport policy. South African Department of Transport, pp 1-53. http://www.kzntransport.gov.za/reading_room/reports/Nonmo torised\%20Transport\%20Policy\%20(Draft).pdf. Accessed Mar 2019

12. De Wet T, Dzinotyiweyi T, Ellison GTH (2021) How might bicycle ownership/access and cycling expertise influence the design of cycling promotion interventions at the University of Johannesburg. J Am Coll Health 69:842-850

13. De Wet T, Dzinotyiweyi T, Ellison GTH (2020) Introducing Johannesburg's new cycle lanes to potential student users: experiences, impact and recommendations. J Am Coll Health. https:// doi.org/10.1080/07448481.2020.1817031

14. Dill J (2009) Bicycling for transportation and health: the role of infrastructure. J Publ Health Pol 30:S95-S110

15. Fishman E, Washington S, Haworth N (2012) Barriers and facilitators to public bicycle scheme use: a qualitative approach. Trans Res F 15:686-698

16. Flamm B, Rivasplata C (2014) Perceptions of bicycle-friendly policy impacts on accessibility to transit services: the first and last mile bridge. Mineta Transportation Institute, San José State University, San José, CA. https://transweb.sjsu.edu/sites/default/ files/1104-bicycle-policy-transit-accessibility-first-last-mile-brief. pdf. Accessed Mar 2019

17. Gatersleben B, Appleton KM (2007) Contemplating cycling to work; attitudes and perceptions in different stages of change. Trans Res A 41:302-312

18. GCRO (Gauteng City-Region Observatory) (2013) Quality of life survey. http://gcro1.wits.ac.za/qolviewer/Default.aspx?Type= 2013S. Accessed Mar 2019

19. GCRO (Gauteng City-Region Observatory) (2015) The Gauteng City-region. www.gcro.ac.za. Accessed Mar 2019

20. Godoy J (2012) The bicycle revolution in Paris - five years later. http://www.ipsnews.net/2012/07/the-bicycle-revolution-in-parisfive-years-later/. Accessed Mar 2019

21. Goodman A, Green J, Woodcock J (2014) The role of bicycle sharing systems in normalising the image of cycling: an observational study of London cyclists. J Trans Health 1:5-8

22. Grzebieta RH, McIntosh AM, Chong S (2011) Pedestrian-cyclist collisions: Issues and risk. In: Proceedings of the Australasian College of Road Safety Conference "A Safe System: Making it Happen!" Melbourne 1-2 September 2011, 12pp

23. Jennings G (2015) A bicycling renaissance in South Africa? Policies, programmes and trends in Cape Town. Proc S Afr Trans Conf 34:486-498

24. Johannesburg Development Agency (2015) Joburg's pedestrians, cyclists catered for. http://www.jda.org.za/index.php/whatwedo/ programmes/greenways/non-motorised-transport. Accessed Mar 2019
25. Johannesburg Roads Agency (2015) Johannesburg Roads Agency Strategy. http://www.jra.org.za/documents/home/JRA\%20final Strategy_4.pdf. Accessed Mar 2019

26. Law GR, Green R, Ellison GT (2012) Confounding and causal path diagrams. In: Tu Y-K, Greenwood DC (eds) Modern methods for epidemiology. Springer, Dordrecht, pp 1-13

27. Lenora Brown R (2016) How bike lanes became an issue of race and class in Johannesburg. Independent 28 October. https://www. independent.co.uk/news/world/africa/how-bike-lanes-became-anissue-of-race-and-class-in-johannesburg-south-africa-a7385641. html. Accessed Mar 2019

28. Madibogo J (2016) There won't be Bicycle Lanes in Sandton, says Malema. Times LIVE 10 Jun. http://www.timeslive.co.za/ politics/2016/06/10/There-won't-be-bicycle-lanes-in-Sandton,says-Malema. Accessed Mar 2019

29. Marshall WE, Garrick NW (2011) Evidence on why bike-friendly cities are safer for all road users. Environ Pract 13:16-27

30. Morgan N (2017) Johannesburg's bike lanes are not well used. Here's why. The Conversation 11 Apr. https://theconversation. com/johannesburgs-bike-lanes-are-not-well-used-heres-why75068. Accessed Mar 2019

31. OBIS (2011) Optimising bike sharing in European Cities: a handbook. https://ec.europa.eu/energy/intelligent/projects/en/projects/ obis\#lesson. Accessed Mar 2019

32. Oja P, Titze S, Bauman A, De Geus B, Krenn P, Reger-Nash B, Kohlberger T (2011) Health benefits of cycling: a systematic review. Scand J Med Sci Sport 21:496-509

33. Petzer B (2015) Why cycling should matter when planning the future of South African Cities. http://www.studiorotterdam.co.za/ blog/whycyclingmatters. Accessed Mar 2019

34. Petzer B (2016) A contextual analysis of cycling environment assessment tools in a Cape Town Mobility Corridor. Unpublished Master of City and Regional Planning, University of Cape Town. https://open.uct.ac.za/bitstream/handle/11427/22895/thesis_ebe_ 2016_petzer_brett.pdf?sequence=1. Accessed Mar 2019

35. Pucher J, Buehler R (2008) Making cycling irresistible: lessons from the Netherlands, Denmark and Germany. Trans Rev 28:495-528

36. Pucher J, Dill J, Handy S (2010) Infrastructure, programs, and policies to increase bicycling: an international review. Prev Med 50:S106-S125

37. Pucher J, Buehler R, Merom D, Bauman A (2011) Walking and cycling in the United States, 2001-2009: evidence from the national household travel surveys. Am J Publ Health 101:S310-S317

38. Servaas M (2000) The significance of non-motorised transport for developing countries: strategies for Policy Development, World Bank. http://siteresources.worldbank.org/INTURBANTRANSPO RT/Resources/non_motor_i-ce.pdf. Accessed Mar 2019

39. Shaheen SA (2012) Public bike sharing in North America: early operator and user understanding. MTI report, Mineta Transportation Institute, San José State University, San José, CA, pp 11-19. https://transweb.sjsu.edu/sites/default/files/1029-public-bikesharing-understanding-early-operators-users.pdf. Accessed Mar 2019

40. Shannon T, Giles-Corti B, Pikora T, Bulsara M, Shilton T, Bull F (2006) Active commuting in a university setting: assessing commuting habits and potential for modal change. Trans Pol $13: 240-253$

41. Stones L (2013) The struggle for a cycle-friendly city. Mail \& Guardian 4 Oct. https://mg.co.za/article/2013-10-04-00-the-strug gle-for-a-cycle-friendly-city. Accessed Mar 2019

42. Textor J (2015) Drawing and analyzing causal DAGs with DAGitty. http://www.dagitty.net/manual-2.x.pdf. Accessed 1 May 2017

43. Textor J, Hardt J, Knüppel S (2011) DAGitty: a graphical tool for analyzing causal diagrams. Epidemiol 22:745 
44. Textor J, van der Zander B, Gilthorpe MS, Liśkiewicz M, Ellison GTH (2016) Robust causal inference using directed acyclic graphs: the R package 'dagitty.' Int J Epidemiol 45:1887-1894

45. Turok I (2012) Urbanisation and development in South Africa: economic imperatives, spatial distortions and strategic responses. Urbanisation and emerging population issues working paper 8, London, Human Settlements Group, International Institute for Environment and Development (IIED). https://pdfs.semanticsc holar.org/4285/c890b1bd847ce44902ff6bf0af04dbf5a2b7.pdf? $\mathrm{ga}=2.23561018 .1064485027 .1553642227-250884056.15493$ 89125. Accessed Mar 2019

\section{Authors and Affiliations}

\section{G. T. H. Ellison ${ }^{1,2} \mathbb{D}^{\mathbb{D}} \cdot$ T. De Wet $^{1}$}

G. T. H. Ellison gthellison@uclan.ac.uk

1 ADS/CAT, University of Johannesburg, Gauteng, South Africa
46. VanderWeele TJ (2008) The sign of the bias of unmeasured confounding. Biometrics 64:702-706

47. Van Mead N (2016) Can Johannesburg Reinvent itself as Africa's first cycle-friendly megacity? Guardian 24 May. https://www. theguardian.com/cities/2016/may/24/johannesburg-africa-firstcycle-friendly-megacity-bicycles. Accessed Mar 2019

Publisher's Note Springer Nature remains neutral with regard to jurisdictional claims in published maps and institutional affiliations.
2 Centre for Data Innovation, University of Central Lancashire, Preston, UK 